There have been many challenges along the way, however, our journey continues and we have many more miles to go. Early feedback from parents and families is positive and they are enjoying the diversity of our service.

\section{P-111 BEYOND THE CLINICAL - HOW WELL DO WE REALLY MEET THE NEEDS OF OUR FAMILIES?}

Vanessa Spinks, Lynn Grayson, John Pye, Siobhan McCoy. Derian House Children's Hospice, Chorley, Lancashire

\subsection{6/spcare-2021-Hospice.128}

Background As practitioners and clinicians who work closely with children, young people and their families, we always assume we know what the families need from hospices.

Aim(s) To review the current service offering of the hospice, to identify gaps in provision, to highlight any barriers there are to accessing services and to shape our delivery to meet the articulated future needs of our families and our commissioners.

Methods We commissioned an independent research company to undertake the research project which included a desktop literature review, quantitative and qualitative interviews with 100 families and interviews with stakeholders across the North West including FOI requests to CCGs. Neonatal and bereaved families were not included in this study.

Results Our families identified respite as the most important service offered by the hospice with wellbeing services identified as the second most important. Our stakeholders and CCGs acknowledged funding for palliative care is patchy across the North West and were concerned whether Derian House can continue to offer the services we currently provide. Additionally, the research also highlighted a big gap in transition services between children's and adults' hospices.. The results of the research have informed the strategy for the hospice for the next three years and CCGs will be using the research to revise and develop their own services for children and young people.

Conclusions The results supported our continued provision of planned respite, it also highlighted areas which may act as barriers to accessing services which include transport and also the information provided to external services explaining the facilities offered to families. These barriers identified by this research project now form part of our strategy over the next three years. We will continue to review services and engagement with families, and will be further exploring needs for neonatal families and the need of families for end-of-life and bereavement.

\section{P-112 PARENT LIVED EXPERIENCES OF UNMET NEEDS, ACCESS AND EXPECTATIONS IN CARE FOR LIFE-LIMITED CHILDREN}

1,2,3 Georgina Constantinou, ${ }^{2}$ Gurch Randhawa, ${ }^{2}$ Erica Cook, ${ }^{3}$ Elaine Tolliday. ${ }^{1}$ City, University of London, London, UK; ${ }^{2}$ University of Bedfordshire, Luton, UK; ${ }^{3}$ Keech Hospice Care, Luton, UK

\subsection{6/spcare-2021-Hospice.129}

Background Harnessing the experiences of parents of life-limited children remains a research priority nationally and internationally. Existing evidence outlines the needs of this group, however, less information is available as to how well these needs are being met by services from the perspective of parents in the UK. The parent responsibility for providing and navigating care for their child is well documented, therefore, it is important we understand the barriers and facilitators faced by families when accessing services for their children.

Aim To examine how children's palliative care services can be improved to meet the needs of children and their families.

Methods A two-part qualitative study underpinned by a social constructivist and phenomenological research approach was employed. Phase 1 conducted an interview-diary study over a two-month period with parents currently caring for a life-limited child $(n=12)$ and Phase 2 carried out semi-structured interviews with bereaved parents of life-limited children $(n=5)$. The data was transcribed verbatim and thematically analysed.

Findings The findings revealed concerns with 'Communication and Information sharing', identified 'Factors Influencing access' i.e., limited funding, staffing availability, delays in services and poor perceptions of palliative care and emphasised the 'Continuous caring and Fighting' involved in being a parent of a child with a life-limiting illness.

Conclusion The parents' lived experiences, documented in this research, provide insight into the unmet needs, barriers, and facilitators to access and understanding of the role of parent expectations in care. These findings indicate that further research is warranted identifying parents' awareness of available information and resources, further investigation into the working practices between services within the children's palliative care pathway and an overall need for suitable respite to be available to families.

\section{P-113 NEW KIDS ON THE BLOCK IN PALLIATIVE CARE}

Fiona Wylie, Sheonad Laidlaw. The Prince and Princess of Wales Hospice, Glasgow, UK

\subsection{6/spcare-2021-Hospice. 130}

Background Advances in medicine means many young adults (YA) in Scotland with a life-limiting condition are living into adulthood (Fraser, Jarvis, Moran, et al., 2015; McLaughlin \& Robb, 2018; McLaughlin, Marosi, Robb, 2020). However, despite this growing trend, access to adult palliative care services is variable (Scottish University Insight Institute, 2019) with reluctance from YAs and professionals to engage (Lidstone, 2013). We explored and evaluated staff experience in caring for a YA within an adult palliative setting.

Aim(s) To explore and evaluate the lived experience of the inpatient unit team caring for a YA during an admission.

Methods Following a young adult admission all staff involved were invited to attend a facilitated reflective discussion to explore their thoughts, feelings and experiences. Questions for reflection were sent in advance of the meeting.

Results Despite the misconceptions pre-admission, the lived experience of physically caring for a young adult offered an entirely different lens and demonstrated the power of human contact in establishing rapport and trust. The admission also afforded insight into the importance of acknowledging the young adult as an expert in their own care and that when staff negotiated and accommodated this the difference observed was:

'I could really feel that the young adult felt physically and emotionally safe.' 
The admission also offered an appreciation that the team already had transferable skills, confidence and experience to carry out this care. The reflection of the last team within the hospice to care for a young adult highlighted:

'A mountain has been climbed; the final piece of the jigsaw is in place'.

Conclusions Evaluation challenges the misconception that adult hospices have nothing to offer young adults with palliative care needs. It also affirms that the skills the team already have are transferable.

\section{P-114 YOU SAID, WE DID: HEARING THE YOUNG ADULT VOICE}

Sheonad Laidlaw, Fiona Wylie. The Prince and Princess of Wales Hospice, Glasgow, UK

\subsection{6/spcare-2021-Hospice.131}

Background Those living with life-limiting conditions and physical disability are living longer (McLaughlin, Marosi, Robb, 2020; Landfelt, Thompson, Sejersen, et al., 2020). Advancing age can bring increasing disability and dependence, contrasted with a desire for autonomy and control. At home, such young adults create useable and safe environments around them, achieving more independent living (Bann, Abresch, Biesecker, et al., 2015; Frank, 2020). The lack of such an environment within a hospice may be a barrier to using the services on offer.

Aims

- To understand what is important to a young adult on admission to a hospice inpatient unit (IPU).

- To create an independent and accessible environment for young adults at The Prince and Princess of Wales Hospice.

Methods SHANARRI wellbeing indicators (Scottish Government. Getting it right for every child (GIRFEC), 2017) - safe, healthy, achieving, nurtured, active, responsible, respected and included - were used as a template to gather feedback following a young adult's IPU stay. This involved a one-to-one conversation, capturing verbatim what they said. A process of change was then commenced, and the results shared with the young adult: 'You said, we did'.

Results The young adult identified that access to the following items in the IPU were essential to ensure wellbeing during their stay:

- Equipment: e.g., profiling bed, mattress, tracking hoist.

- Technology: e.g., gaming, computer, phones, WiFi.

- Environmental controls: e.g., lighting, heating, call system, monitoring.

Conclusions Feedback in the form of 'You said, we did' demonstrates commitment to listening and responding, enables rich communication, generates feelings for the young adult of being respected and appreciated, and accelerates adoption of a wide range of changes by the hospice for the young adults. Using verbatim what the young adult said made the case for change personal and more credible. Connection to, and control of, their world, through technology and environmental controls, contributes to their overall mental health and wellbeing. Reproducing their home environments ensures that, when in new surroundings, they are not wholly dependent on others but rather they are safe, achieving, and more independent.

\section{P-115 BUILDING CARERS' RESILIENCE AND WELL-BEING INTEGRATED WITHIN A RESPITE PROGRAMME}

Helen Reeves, Katie Burbridge, Debra Varnam. St Giles Hospice, Whittington, UK

10.1136/spcare-2021-Hospice. 132

Improving end-of-life care is a strategic priority for commissioners and has been for some years. The mean number of hospital admissions in the last 12 months of life averaged in England is 2.28 occupying 30.05 bed days (Bardsley, Georghiou, Spence, et al., 2019). A Carers UK (2016) survey identified that carer breakdown led to unnecessary, distressing and expensive admissions to hospital of the person being cared for, and suggested that if the carer had greater and higher quality support, it could have a significant impact on the number of emergency admissions.

St Giles Hospice recognised that there was still more needed to enable families and patients to feel supported at home. After speaking to families, patients and community healthcare professionals, the organisation identified a gap in service provision for respite care. Consequently, in March 2021 St Giles launched a new respite service which was funded by the generosity of a local business. The aim of that service was to provide support to patients and carers in the last 12 months of life by providing respite care and education within the home setting. This will be achieved through:

- Building resilience and wellbeing within the carer.

- Increasing knowledge and skills for informal carers to support them in the provision of care to those they are caring for.

- Offering respite care in the home causing minimal disturbance to the patient and provide the carer with a muchneeded break.

- Supporting patients and carers to maximise the scope for selfcare and to combine formal and informal support.

- Acting as a flexible, responsive service.

- Supporting the wider shift from hospital to primary care by avoiding hospital admissions.

- Ensuring staff are trained as 'train the trainers' with additional skills in dementia care as it is acknowledged that dementia is not only a primary but a secondary diagnosis and the number of people of dementia is increasing as people live longer.

\section{P-116 SUPPORTING CARERS DURING A PANDEMIC - TRANSFORMING DEMENTIA CARERS' SUPPORT}

${ }^{1}$ Helen Reeves, ${ }^{1}$ Gina Gardner, ${ }^{2}$ Fiona McCracken, ${ }^{2}$ Asima Hussain, ${ }^{2}$ Pat Roberts. ${ }^{1}$ St Giles Hospice, Whittington, UK; ${ }^{2}$ GreenSquare Accord, Walsall, UK

\subsection{6/spcare-2021-Hospice. 133}

Dementia is a far-reaching disease and it is estimated that approximately 850,000 people are living with dementia in the $\mathrm{UK}$; this is estimated to increase to over 1 million by the year 2025 (Prince, Knapp, Guerchet, et al., 2014).

Caring for people with dementia is demanding and this care is often provided by unpaid carers in the home (National Institute for Health Research, 2016). So often people are uncertain about what the future could hold following diagnosis and how to support a person with dementia. Due to this 